- Original Paper •

\title{
A Cloud Detection Scheme for the Chinese Carbon Dioxide Observation Satellite (TANSAT)
}

\author{
Xi WANG ${ }^{1,2}$, Zheng GUO ${ }^{2}$, Yipeng HUANG ${ }^{1}$, Hongjie FAN ${ }^{1}$, and Wanbiao $\mathrm{LI}^{* 1}$ \\ ${ }^{1}$ Laboratory for Climate and Ocean-Atmosphere Studies, Department of Atmospheric and Oceanic Sciences, \\ School of Physics, Peking University, Beijing 100871, China \\ ${ }^{2}$ National Satellite Meteorological Center, China Meteorological Administration, Beijing 100081, China
}

(Received 30 January 2016; revised 29 July 2016; accepted 16 August 2016)

\begin{abstract}
Cloud detection is an essential preprocessing step for retrieving carbon dioxide from satellite observations of reflected sunlight. During the pre-launch study of the Chinese Carbon Dioxide Observation Satellite (TANSAT), a cloud-screening scheme was presented for the Cloud and Aerosol Polarization Imager (CAPI), which only performs measurements in five channels located in the visible to near-infrared regions of the spectrum. The scheme for CAPI, based on previous cloudscreening algorithms, defines a method to regroup individual threshold tests for each pixel in a scene according to the derived clear confidence level. This scheme is proven to be more effective for sensors with few channels. The work relies upon the radiance data from the Visible and Infrared Radiometer (VIRR) onboard the Chinese FengYun-3A Polar-orbiting Meteorological Satellite (FY-3A), which uses four wavebands similar to that of CAPI and can serve as a proxy for its measurements. The scheme has been applied to a number of the VIRR scenes over four target areas (desert, snow, ocean, forest) for all seasons. To assess the screening results, comparisons against the cloud-screening product from MODIS are made. The evaluation suggests that the proposed scheme inherits the advantages of schemes described in previous publications and shows improved cloud-screening results. A seasonal analysis reveals that this scheme provides better performance during warmer seasons, except for observations over oceans, where results are much better in colder seasons.
\end{abstract}

Key words: TANSAT, CAPI, cloud detection, regrouping scheme

Citation: Wang, X., Z. Guo, Y. P. Huang, H. J. Fan, and W. B. Li, 2017: A cloud detection scheme for the Chinese Carbon Dioxide Observation Satellite (TANSAT). Adv. Atmos. Sci., 34(1), 16-25, doi: 10.1007/s00376-016-6033-y.

\section{Introduction}

Carbon dioxide $\left(\mathrm{CO}_{2}\right)$ is one of the primary greenhouse gases, which has raised concern due to the rapid increase in its atmospheric concentrations. The global observation of $\mathrm{CO}_{2}$ has been a crucial issue for the investigation of the carbon cycle mechanism and the prediction of global climate change (Farquhar, 1997; Cox et al., 2000; Le Quéré et al., 2009; Solomon et al., 2009). Satellite remote sensing provides a new technique for the global monitoring of the column averaged $\mathrm{CO}_{2}$ dry air mole fraction $\left(\mathrm{XCO}_{2}\right)$ in the atmosphere (Bovensmann et al., 1999; Chahine et al., 2005; Barkley et al., 2006; Chahine et al., 2006; Crisp et al., 2008; Yokota et al., 2009; Reuter et al., 2010; Butz et al., 2011; Yoshida et al., 2013).

The Chinese Carbon Dioxide Observation Satellite (TANSAT) project is one of the National High-tech Research and Development Programs funded by the Ministry of Science and Technology of the People's Republic of China

\footnotetext{
* Corresponding author: Wanbiao LI

Email: 1wb@pku.edu.cn
}

and the Chinese Academy of Sciences (Liu et al., 2013; Bi et al., 2014). TANSAT was designed to focus on the global observation of $\mathrm{CO}_{2}$. It is scheduled to be a sun-synchronous polar-orbiting environmental satellite operating at an altitude of about $700 \mathrm{~km}$. There will be two key instruments onboard the spacecraft; namely, the Carbon Dioxide Sensor (CDS) and the Cloud and Aerosol Polarization Imager (CAPI) (Cai et al., 2014). CAPI was designed to retrieve cloud and aerosol characteristics, allowing for more accurate $\mathrm{CO}_{2}$ retrievals. It measures in a wide swath, encompassing the narrow swath of the CDS, in order to provide a sufficiently large region for the detection of aerosol spatial distribution, cloud coverage, and surface conditions. CAPI has five visible and nearinfrared channels $(0.38 \mu \mathrm{m}, 0.67 \mu \mathrm{m}, 0.87 \mu \mathrm{m}, 1.375 \mu \mathrm{m}$ and $1.64 \mu \mathrm{m}$ ), similar to that of the Cloud and Aerosol Imager of the Thermal And Near-infrared Sensor for Carbon Observation (TANSO-CAI) onboard the Greenhouse Gases Observing Satellite (GOSAT) (Kuze et al., 2009). Additionally, there is a $1.375 \mu \mathrm{m}$ band for detecting cirrus, and two polarization channels at $0.67 \mu \mathrm{m}$ and $1.64 \mu \mathrm{m}$ for CAPI (Shi et al., 2014).

Discrepancies (uncertainties) can be introduced by 
clouds, aerosols and water vapor, which need to be reduced to a minimum in the preprocessing process in order to improve the precision of the $\mathrm{XCO}_{2}$ retrieval. Cloud detection plays a crucial role in the preprocessing process. Since the advent of the satellite era, many cloud-screening algorithms have been developed. Here, we briefly present those that are most relevant to TANSAT.

The ISCCP adopted the radiance from visible $(0.6 \mu \mathrm{m})$ and infrared window $(11 \mu \mathrm{m})$ bands to discriminate clouds from clear-sky areas based on statistical threshold tests on the geostationary platform (Rossow et al., 1989; Rossow et al., 1989; Sèze and Rossow, 1991; Rossow and Garder, 1993). For AVHRR, there are two major schemes for cloud screening: the AVHRR Processing scheme Over Clouds, Land and Ocean (APOLLO) and the Clouds from AVHRR (CLAVR) scheme. Using the threshold tests from two visible and three infrared bands of AVHRR, APOLLO defines a pixel as cloudcontaminated if it fails any single test (Saunders and Kriebel, 1988; Gesell, 1989; Kriebel et al., 1989, 2003). In addition to the threshold concept, CLAVR introduces spatial tests that rely on the fact that uniform scenes are less likely to contain partial or sub-pixel clouds using $2 \times 2$ pixel arrays (Stowe et al., 1991, 1994).

The cloud-mask algorithm for MODIS, which can be referred to as "MOD35", benefited from previous research and proposed the concept of the clear confidence level (CCL) to evaluate the cloud detection results. The threshold tests are divided into five groups, and the final cloud mask is determined by the minimum confidence of each group (Ackerman et al., 1998, 2008; Platnick et al., 2003). Ishida and Nakajima (2009) proposed an unbiased concept to composite the results of each single threshold test for MODIS. The Cloud and Aerosol Unbiased Decision Intellectual Algorithm (CLAUDIA) defines the final cloud mask by the outcomes of two groups that employ different methods to calculate the CCL (Nakajima et al., 2011). A daytime cloud detection algorithm has been developed for the Visible and Infrared Radiometer (VIRR) onboard the Chinese FengYun-3A satellite (FY-3A), which shows good performance over the oceans by adding the test of the reflectance difference between the 1.38 and 1.6 $\mu \mathrm{m}$ bands (He, 2011).

For cloud-mask algorithms that employ multispectral threshold tests, the prevalent schemes can be generally classified into three categories: the clear-conservative (APOLLO and MOD35), the cloud-conservative (ISCCP), and the unbiased (CLAUDIA) schemes. Before the application of the CCL, a pixel was identified as cloudy if it failed any single test for clear-sky conditions, which could be classified as a clear-conservative scheme. It was similar for the cloudconservative schemes. The CCL provides a reasonable technique to evaluate the contamination of clouds for each pixel. Based on the concept of the CCL, the clear-conservative, cloud-conservative, and unbiased schemes (Nakajima et al., 2011) could be determined by:

$$
Q=\sqrt[N]{\prod_{i=1}^{N} F_{i}} \quad \text { (clear conservative) }
$$

$$
\begin{aligned}
& Q=1-\sqrt[N]{\prod_{i=1}^{N}\left(1-F_{i}\right)} \quad(\text { cloud conservative) } \\
& Q=\sqrt{Q_{1} Q_{2}}, \quad\left\{\begin{array}{l}
Q_{1}=\sqrt[N_{1}]{\prod_{i=1}^{N_{1}} F_{i}} \\
Q_{2}=1-\sqrt[N_{2}]{\prod_{i=1}^{N_{2}}\left(1-F_{i}\right)}
\end{array}\right.
\end{aligned}
$$

The final CCL is denoted as $Q . F_{i}$ represents the CCL value for an individual threshold test. $N$ represents the numbers of tests. For the unbiased scheme, $Q_{1}$ and $Q_{2}$ represent the CCL values for the clear and cloud conservative types, respectively. $N_{1}$ and $N_{2}$ represent the numbers of individual clear and cloud conservative tests, respectively.

The cloud-mask algorithms, such as MOD35 and CLAUDIA, classify the multispectral threshold tests into different groups, and the final cloud mask is defined by the CCL values from groups. However, the grouping rules for the tests of the previous algorithms may not work well for sensors with few channels or frequencies available for cloud screening. Moreover, the direct grouping techniques could lead to a single scheme for calculating the final CCL, which could be either a cloud-conservative or a clear-conservative method. In order to make full use of the information from the channels and tests, a scheme is presented here to realize the reasonable combination of the few threshold tests. Instead of predefining spectral tests as clear- or cloud-conservative, the tests are classified on a pixel-by-pixel basis according to the resultant CCL value. In this paper, the scheme is applied for prelaunch testing of the CAPI cloud-screening algorithm. Observations from similar bands of FY-3A/VIRR are used as proxies for real CAPI measurements. Section 2 details the algorithm and the scheme for CAPI. Section 3 provides the results and validation of the proposed scheme. A summary is given in section 4 .

\section{Methodology}

\subsection{Data}

The TANSAT/CAPI instrument was designed to be a fiveband imager, with bands centered at $0.38 \mu \mathrm{m}, 0.67 \mu \mathrm{m}, 0.87$ $\mu \mathrm{m}, 1.375 \mu \mathrm{m}$ and $1.64 \mu \mathrm{m}$. It also has two polarization channels at $0.67 \mu \mathrm{m}$ and $1.64 \mu \mathrm{m}$. Here, in the pre-launch period of TANSAT, proxy measurements from FY-3A/VIRR are used. As a new generation of polar-orbiting meteorological satellite, FY-3A is capable of a wide range of spectral detection-from ultraviolet, visible and infrared, to the microwave spectrum. It descends across the equator at about 1005 LST (Local Standard Time) and operates at an altitude of $831 \mathrm{~km}$. VIRR, which is a key instrument onboard FY-3A, has 10 observation bands located in the wavelength range of $0.44-12.5 \mu \mathrm{m}$, a scanning range of $\pm 55.4^{\circ}$, and a resolution of $1.1 \mathrm{~km}$ (Dong et al., 2009). Considering the similar bands, the data from channels 1, 2, 6 and 10 of VIRR are used as prelaunch proxy measurements for CAPI. The specifications of the channels are listed in Table 1. 
Table 1. Specifications for the channels of TANSAT/CAPI and FY-3A/VIRR.

\begin{tabular}{ccccccc}
\hline \multicolumn{3}{c}{ TANSAT/CAPI } & & \multicolumn{2}{c}{ FY-3A/VIRR } \\
\cline { 1 - 2 } Channel & Wavelength $(\mu \mathrm{m})$ & Spectral range $(\mu \mathrm{m})$ & & Channel & Wavelength $(\mu \mathrm{m})$ & Spectral range $(\mu \mathrm{m})$ \\
\hline 1 & 0.38 & $0.365-0.408$ & & - & - & - \\
2 & 0.67 & $0.66-0.685$ & & 1 & 0.63 & $0.58-0.68$ \\
3 & 0.87 & $0.862-0.877$ & & 2 & 0.865 & $0.84-0.89$ \\
4 & 1.375 & $1.36-1.39$ & & 10 & 1.36 & $1.325-1.395$ \\
5 & 1.64 & $1.628-1.654$ & & 6 & 1.595 & $1.55-1.64$ \\
\hline
\end{tabular}

\subsection{Calculation of the $\mathrm{CCL}$}

For the traditional cloud detection algorithms, which employed the threshold concept, there are mainly three methods for combining the results derived from the multispectral-threshold tests: the clear-conservative, the cloud-conservative, and the unbiased schemes (refer to section 1). The previous schemes were basically designed to provide comprehensive utilization for sensors that contain multiple channels over a wide spectral range. For CAPI, the channels available for cloud screening cover only five spectral bands, which is why such sensors need a more effective method to regroup results from few threshold tests.

The scheme for CAPI focuses on each single pixel in the field of view. It classifies individual tests into two groups. If the CCL value for a single test on a given pixel is less than 0.5 , which means the pixel is probably going to be cloudy, the scheme for calculating the final CCL is preferred to be the cloud-conservative type in order to avoid the overestimation of cloudy regions. Similarly, when the CCL value for a single test on a particular pixel is higher than 0.5 , the spectral test is assigned to the clear-conservative type. The final CCL, denoted as $Q$, is described as follows:

$$
Q=\sqrt{Q_{1} Q_{2}}, \quad\left\{\begin{array}{ll}
Q_{1}=\sqrt[N_{1}]{\prod_{i=1}^{N_{1}} F_{i}}, & F_{i} \geqslant 0.5 \\
Q_{2}=1-\sqrt[N_{2}]{\prod_{i=1}^{N_{2}}\left(1-F_{i}\right)}, & F_{i} \leqslant 0.5
\end{array} .\right.
$$

Here, $Q_{1}$ and $Q_{2}$ represent the CCL values for the clear- and cloud-conservative types, respectively; $F_{i}$ represents the CCL value from each single threshold test; and $N_{1}$ and $N_{2}$ represent the numbers of individual clear- and cloud-conservative tests, respectively.

The final CCL of the proposed scheme is determined by the result of each single threshold test. This approach is more efficient for sensors with few channels or frequencies available for cloud screening, which could only be classified into one group according to the traditional grouping rules, and therefore limited to one conservative scheme for calculating the final CCL.

\subsection{Threshold tests for CAPI}

Based on the concept of the CCL proposed by MOD35 (Fig. 1a) and CLAUDIA (Fig. 1b), two main categories of threshold tests are applied to the CAPI cloud detection algorithm.

Single band reflectance tests: Single band reflectance tests for discriminating clouds from clear-sky areas have been well studied (Ackerman et al., 1998; Hutchison et al., 2005; Frey et al., 2008; He, 2011; Nakajima et al., 2011; Wang et al., 2012). In the non-absorption visible and near-infrared bands, the reflectance of clouds typically shows a higher value than that of clear-sky surfaces. Based on this fact, the reflectance of $0.67 \mu \mathrm{m}$ and $0.87 \mu \mathrm{m}$ can be used for cloud screening of CAPI. In order to provide more accurate thresholds adapted to various surfaces, the minimum albedo map

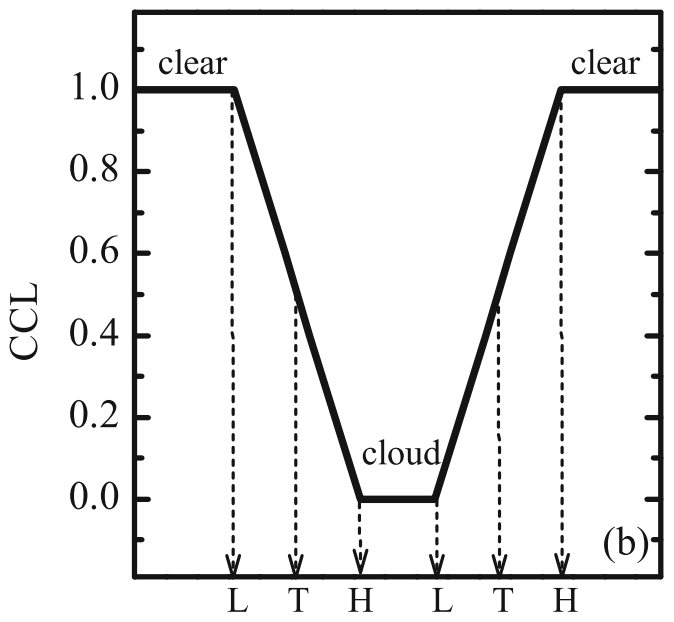

Fig. 1. The concept of the CCL for (a) one threshold and (b) two thresholds (L, T and H represent the lower limit, threshold and higher limit, respectively). 
proposed by Ishida and Nakajima (2009) is applied here instead of the traditional static thresholds. Here, the minimum albedo map, with a spatial resolution of $0.05^{\circ} \times 0.05^{\circ}$, is determined by the monthly minimum reflectance of VIRR.

The $1.38 \mu \mathrm{m}$ band, which is influenced by the strong absorption of water vapor, has been widely used in cirrus detection (Gao et al., 1993). For high clouds and cirrus, which are mainly composed of ice crystals, the radiance reflected by the surface or low clouds will be almost completely absorbed by the abundant water vapor below. When high clouds exist, the radiance in the $1.38 \mu \mathrm{m}$ band increases, which can be an effective method for cirrus detection. However, the technique is not suitable for high altitude areas due to the reduced absorption of less air mass and the increased radiance reflected by the surface.

Reflectance ratio tests: The reflectance at $0.87 \mu \mathrm{m}$ and $0.67 \mu \mathrm{m}$ is similar for clouds but different for various clearsky surfaces. Thus, the reflectance ratio of these two bands can be used for detecting clouds. This test is adapted for cloud screening over oceans, but is unreliable over bright surfaces such as desert. The reflectance ratio of $0.87 \mu \mathrm{m}$ and $1.64 \mu \mathrm{m}$ could be more effective to resolve the problem for cloud discrimination over desert. For desert, the reflectance increases with increasing wavelength, while for clouds the variation is not so sensitive. Another prevalent reflectanceratio threshold test is based on the NDVI, which can be applied to identify clouds over vegetated surfaces.

In order to produce optimized cloud-mask results in the pre-launch period of TANSAT, the thresholds in the algorithm need to be examined and adjusted, which relies extensively on the use of the synthetic data of CAPI. The modification of thresholds is necessary due to the differences in sensors, spectra, and some unique design characterizations (Hutchison et al., 2012). The relevant work is still under research. Here, the threshold of $1.38 \mu \mathrm{m}$ refers to the value employed in MOD35. The thresholds of the remaining tests are taken directly from the CLAUDIA algorithm, considering the similar spectral bands between CAPI and TANSO-CAI (Nakajima et al., 2011).

Before applying the threshold tests, there are two necessary steps to prepare the CAPI image. The first step is to apply the sea/land pixel mask, which can be obtained by the geo-location data from CAPI. Here, it relies on the preprocessing data-block provided by the level-1 data of VIRR. Another preprocessing step is the identification of snow-covered pixels. The Normalized Difference Snow Index (NDSI) is applied here to discriminate snow-covered areas (Hall et al., 1995, 2002; Hall and Riggs, 2011). The NDSI is determined by the reflectance in bands $2(0.66-0.685 \mu \mathrm{m})$ and 5 $(1.628-1.654 \mu \mathrm{m})$ of CAPI. Here, the reflectance from bands $1(0.58-0.68 \mu \mathrm{m})$ and $6(1.55-1.64 \mu \mathrm{m})$ of VIRR is used. Recent work has suggested that the optimum threshold for the NDSI varies seasonally, with 0.48 in July and 0.6 in September (Vogel, 2002). In this work, we label a pixel as snow when the NDSI is higher than 0.48 in warmer seasons (April and July) and 0.6 in colder seasons (January and October), but with two additional requirements: the reflectance of 0.87 $\mu \mathrm{m}$ and $0.67 \mu \mathrm{m}$ are above 0.11 and 0.10 , respectively (Riggs and Hall, 2004).

Additionally, the detection of cloud shadows is also included, based on the reflectance of $0.87 \mu \mathrm{m}$, and is refined by using a ratio test between $0.87 \mu \mathrm{m}$ and $0.67 \mu \mathrm{m}$ (Hulley and Hook, 2008). The specific values of thresholds are listed in Table 2.

\section{Experiments and validation}

The cloud-screening results and validation of CAPI for typical surface types are discussed in this section. MODIS,

Table 2. Thresholds of individual tests for different surface conditions used for cloud screening of TANSAT/CAPI. The tests include the reflectance of $0.67 \mu \mathrm{m}, 0.87 \mu \mathrm{m}$ and $1.38 \mu \mathrm{m}(\mathrm{R} 0.67, \mathrm{R} 0.87$ and R1.38), the reflectance ratio of $0.87 \mu \mathrm{m}$ and $0.67 \mu \mathrm{m}(\mathrm{R} 0.87 / \mathrm{R} 0.67)$, the reflectance ratio of $0.87 \mu \mathrm{m}$ and $1.64 \mu \mathrm{m}$ (R0.87/R1.64), and NDVI. Two additional tests are applied for snow and cloud shadow identification.

\begin{tabular}{|c|c|c|c|c|}
\hline \multirow[b]{2}{*}{ Test } & \multicolumn{4}{|c|}{ Threshold } \\
\hline & Ocean & Land & Desert & Snow \\
\hline R0.67 & - & $\operatorname{Rmin}^{\mathrm{a}}+0.18 \pm 0.075$ & $\operatorname{Rmin}^{\mathrm{a}}+0.18 \pm 0.075$ & $\operatorname{Rmin}^{\mathrm{a}}+0.18 \pm 0.075$ \\
\hline R0.87 & $\operatorname{Rmin}^{\mathrm{a}}+0.12 \pm 0.075$ & - & - & - \\
\hline $\mathrm{R} 1.38$ & $\begin{array}{c}0.0125-0.0075 \\
0.0125+0.0225\end{array}$ & - & - & - \\
\hline NDVI & $\begin{array}{c}-0.16 \pm 0.06 \\
0.34 \pm 0.12\end{array}$ & $\begin{array}{c}-0.16 \pm 0.06 \\
0.34 \pm 0.12\end{array}$ & - & $\begin{array}{c}-0.16 \pm 0.06 \\
0.34 \pm 0.12\end{array}$ \\
\hline R0.87/R0.67 & $\begin{array}{c}0.78 \pm 0.12 \\
1.25 \pm 0.1\end{array}$ & $\begin{array}{c}0.78 \pm 0.12 \\
1.4 \pm 0.3\end{array}$ & - & $\begin{array}{c}0.78 \pm 0.12 \\
1.4 \pm 0.3\end{array}$ \\
\hline R0.87/R1.64 & - & - & $0.96 \pm 0.1$ & - \\
\hline $\begin{array}{l}\text { Snow identification } \\
\text { Cloud shadow }\end{array}$ & \multicolumn{4}{|c|}{$\begin{array}{l}\text { NDSI }>0.48 \text { (April and July) or NDSI }>0.6 \text { (January and October) with R0.87 }>0.11 \text { and R0.67 }>0.1 \\
\text { R0.87 }<0.05 \text { and R0.87/R0.67 }>1.1\end{array}$} \\
\hline
\end{tabular}

${ }^{\mathrm{a}} \mathrm{Rmin}$ represents the minimum reflectance map;

$x+y$ and $x-y$ represent the higher limit and the lower limit, respectively. 
which has 36 channels that cover wavelengths from the visible to thermal infrared regions, allows for a more precise cloud-screening result. Thus, MODIS data are commonly used to evaluate cloud-screening results of other sensors (Ishida et al., 2011; Wang et al., 2012). To investigate the cloud-screening ability of GOSAT/TANSO-CAI, an inter-satellite comparison with Aqua/MODIS, which uses the same algorithm (CLAUDIA), has been performed by Ishida et al. (2011). Here, we focus on the assessment of the cloudscreening scheme for the CAPI. Instead of employing the same cloud-screening algorithm to both sensor data, the operational cloud-mask product from Terra/MODIS, is applied as "truth" for comparison in this work.

Figure 2 illustrates the four target areas in China selected for comparison. The land classification data in Fig. 2 were generated from the GlobCover 2009 products, which are based on ENVISAT's Medium Resolution Imaging Spectrometer Level 1B data acquired in Full Resolution mode, with a spatial resolution of $300 \mathrm{~m}$ (Arino et al., 2010). The surfaces of the target areas are mainly covered by desert (Area-1: $37^{\circ}-42^{\circ} \mathrm{N}, 80^{\circ}-85^{\circ} \mathrm{E}$ ), snow (Area-2: $27^{\circ}-$ $32^{\circ} \mathrm{N}, 93^{\circ}-98^{\circ} \mathrm{E}$ ), ocean (Area-3: $\left.26^{\circ}-31^{\circ} \mathrm{N}, 122^{\circ}-127^{\circ} \mathrm{E}\right)$, and forest (Area-4: $49^{\circ}-54^{\circ} \mathrm{N}, 121^{\circ}-126^{\circ} \mathrm{E}$ ). The comparisons are based on three cloud-screening schemes: the clearconservative (scheme I), the cloud-conservative (scheme II), and the proposed (scheme III) schemes.

The cloud-screening cases over the four target areas are shown in Fig. 3. The first column represents the composite true-color images of the VIRR channels at $0.63 \mu \mathrm{m}$ (red),
$0.555 \mu \mathrm{m}$ (green), and $0.455 \mu \mathrm{m}$ (blue). The images of columns 2-5 are the cloud-screening results obtained by schemes I, II and III, and the images of the Terra/MODIS operational cloud-mask product, respectively. In order to compare with MODIS, the final CCL of the three schemes is divided into four categories: above 0.75 (confident clear), between 0.5 and 0.75 (probably clear), between 0.25 and 0.5 (probably cloudy), and less than 0.25 (cloudy). It is apparent that the result obtained by the clear-conservative scheme shows fewer clear-sky areas than that obtained by the cloudconservative scheme. Combining the advantages of these two traditional algorithms, the proposed scheme provides relatively good agreement with the composite true-color images. Compared with the operational cloud-mask products of MODIS, the proposed scheme also shows better performance than the two traditional regrouping methods. However, for the target areas over desert and forest, some brighter cloudy pixels are identified as snow. The similar reflectance of these brighter cloudy pixels makes it difficult to separate from snow pixels.

For quantitative validation, the operational cloud-mask product of Terra/MODIS is applied here. Terra is a polarorbiting satellite, passing the equator at $1030 \mathrm{LST}$. The orbit of Terra overlaps with that of FY-3A only intermittently. To collocate Terra/MODIS with FY3A/VIRR data, the time difference is limited within 10 minutes. The data are both projected onto grids with a spatial resolution of $0.01^{\circ} \times 0.01^{\circ}$. The operational cloud-mask product of MODIS contains four levels of "confidence": cloudy, probably cloudy, probably

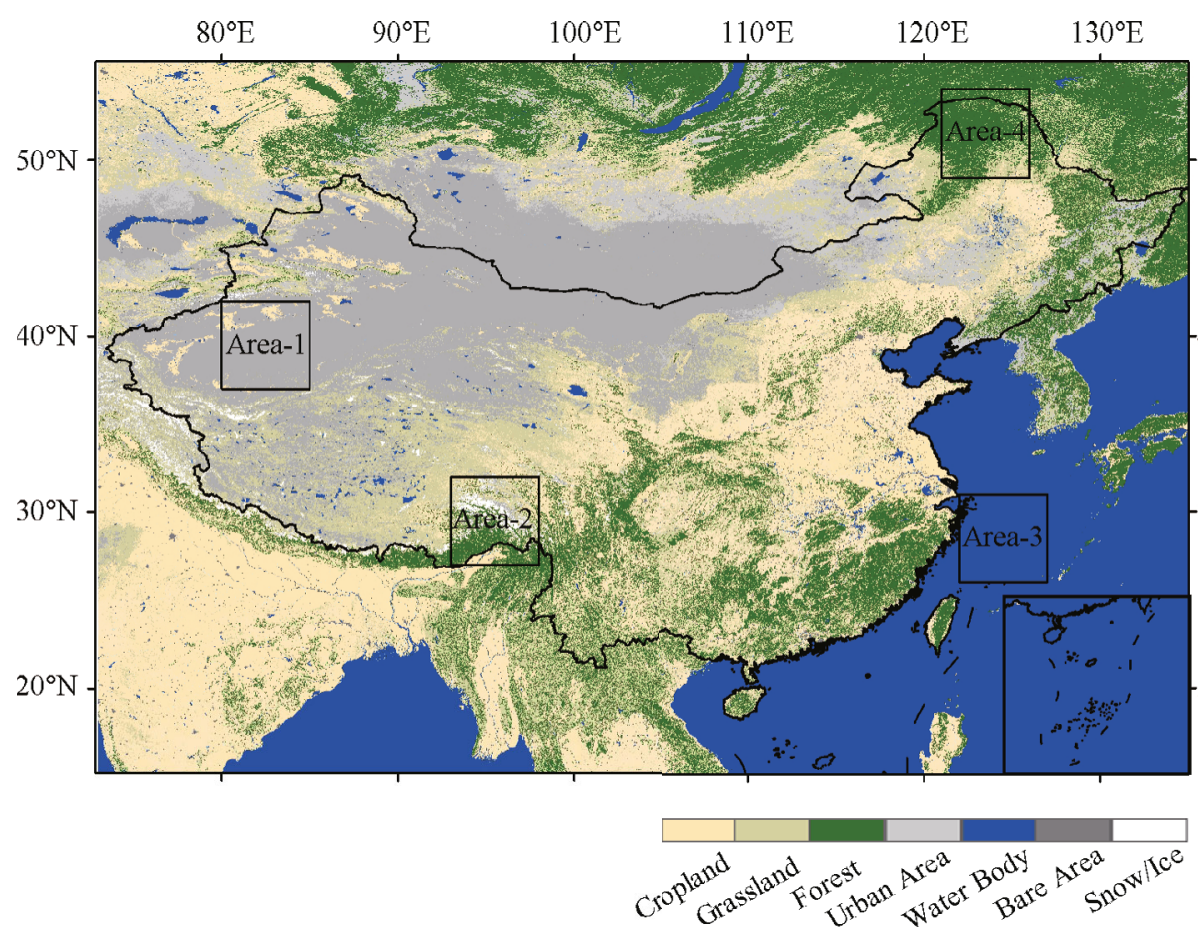

Fig. 2. Specific target areas in China for evaluating the proposed scheme: Area- 1 (desert: $37^{\circ}-$ $42^{\circ} \mathrm{N}, 80^{\circ}-85^{\circ} \mathrm{E}$ ); Area-2 (snow: $27^{\circ}-32^{\circ} \mathrm{N}, 93^{\circ}-98^{\circ} \mathrm{E}$ ); Area-3 (ocean: $26^{\circ}-31^{\circ} \mathrm{N}, 122^{\circ}-$ $127^{\circ} \mathrm{E}$ ); Area-4 (forest: $49^{\circ}-54^{\circ} \mathrm{N}, 121^{\circ}-126^{\circ} \mathrm{E}$ ). 


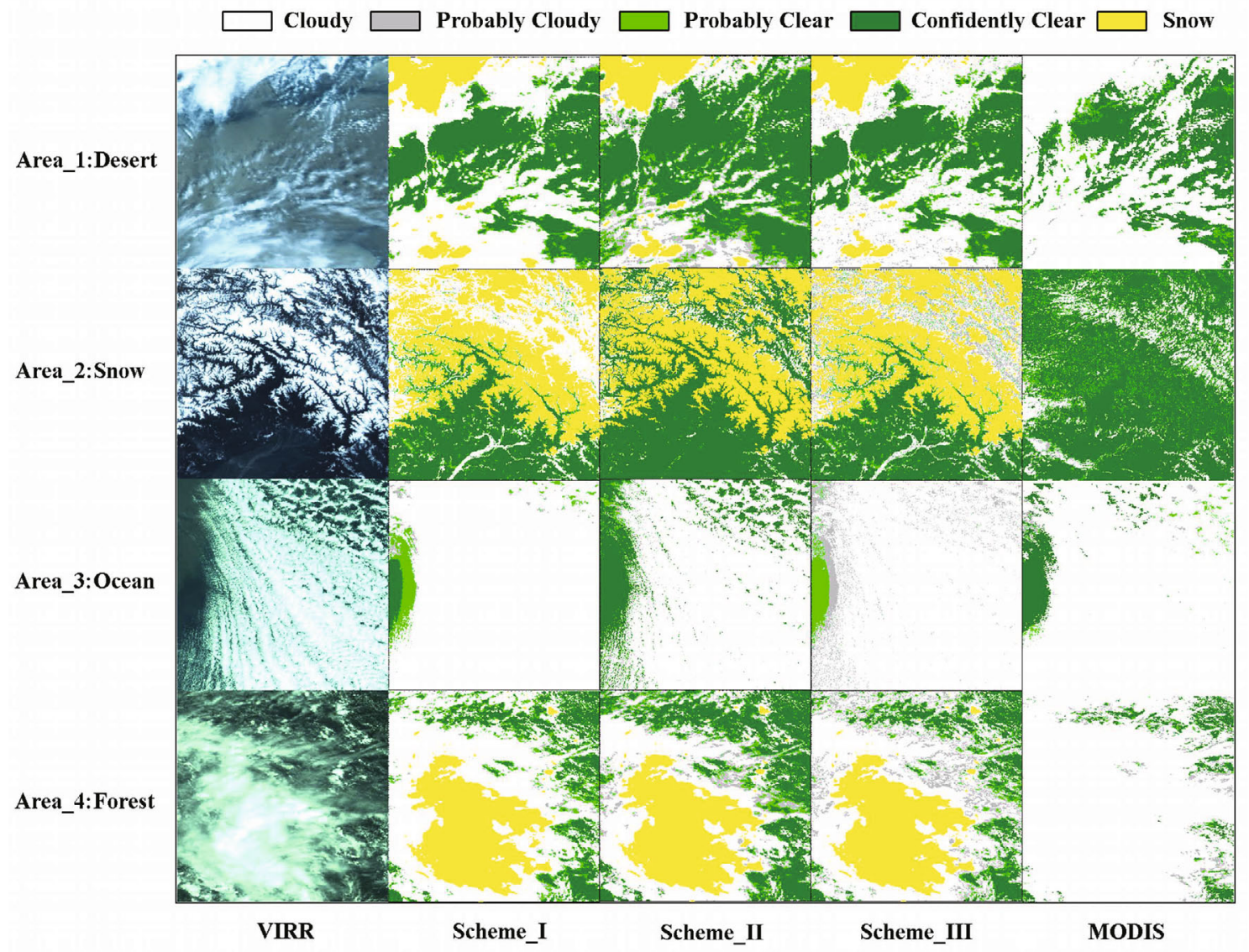

Fig. 3. Column 1: Composite true-color images of FY-3A/VIRR channels at $0.63 \mu \mathrm{m}$ (red), $0.555 \mu \mathrm{m}$ (green), and $0.455 \mu \mathrm{m}$ (blue). Columns 2-4: Cloud-screening results obtained by schemes I, II and III. Column 5: Operational cloud-masking products from MODIS. Line 1: Case over desert at 0555 UTC 15 July 2011 for VIRR and at 0555 UTC 15 July 2011 for MODIS. Line 2: Case over snow at 0425 UTC 26 April 2011 for VIRR and at 0420 UTC 26 April 2011 for MODIS. Line 3: Case over ocean at 0210 UTC 1 January 2011 for VIRR and at 0210 UTC 1 January 2011 for MODIS. Line 4: Case over forest at 0230 UTC 15 July 2011 for VIRR and at 0235 UTC 15 July 2011 for MODIS. The pixels represent cloudy (white), probably cloudy (gray), probably clear (light green), confidently clear (dark green), and snow (yellow).

clear, and confidently clear. For the comparisons here, cloudy pixels are defined as MODIS cloudy, while the MODIS confidently clear pixels are defined to be clear. For the results from the proposed and traditional schemes, the pixels with a CCL between 0 and 0.25 are defined as cloudy ones, while clear ones are defined as pixels with a CCL above 0.75 . Four validation scores are used here: the probability of detection (POD), the false-alarm ratio (FAR), the hit rate (HR), and Kuiper's skill score (KSS). The definitions are

$$
\begin{gathered}
\operatorname{POD}_{\text {clear }}=d /(c+d), \\
\operatorname{POD}_{\text {cloud }}=a /(a+b), \\
\operatorname{FAR}_{\text {clear }}=b /(b+d), \\
\operatorname{FAR}_{\text {cloud }}=c /(a+c), \\
\mathrm{HR}=\frac{a+d}{a+b+c+d}, \text { where } 0 \leqslant \mathrm{HR} \leqslant 1, \\
\mathrm{KSS}=\frac{a d-c b}{(a+b)(c+d)}, \text { where }-1 \leqslant \mathrm{KSS} \leqslant 1,
\end{gathered}
$$

where $a$ and $d$ respectively represent the number of pixels that were determined as cloudy or clear by both the proposed scheme and MODIS; $b$ represents the number of pixels identified as clear by the proposed scheme but as cloudy by MODIS; and $c$ represents the number of pixels identified as cloudy by the proposed scheme but as clear by MODIS. The POD and FAR scores estimate the efficiency of the cloudscreening algorithm in determining either cloudy or cloudfree conditions (Karlsson and Dybbroe, 2010). The POD values are supposed to be as high as possible. Conversely, the FAR values are supposed to be minimized. The HR value is the measurement of the overall efficiency of the cloudmasking algorithm. Moreover, the KSS index is a complementary measurement that to some extent punishes misclassifications even if they are in a small minority of all the studied cases. It is applied here to evaluate how well the scheme performs in separating cloudy events from cloud-free events. A value of 1.0 represents a perfect discrimination, while a value of -1.0 describes a complete discrimination failure. For more detailed information, refer to Karlsson and Dybbroe (2010).

Table 3 lists the number of matchup pixels for the four 
target areas in January, April, July and October of 2011. The scores of POD, FAR, HR and KSS for schemes I, II and III, based on the total matchup dataset of all seasons, are illustrated in Fig. 4. Using the proposed scheme, the POD scores for the cloudy and cloud-free pixels attain a comparable level, as it inherits the advantages of the two traditional schemes. The HR scores by the proposed scheme attain values greater than $80 \%$, except for the target area over forest, where the HR is approximately $71 \%$. The KSS of the proposed scheme maintains a relatively high value for all target areas. For the total matchup dataset, the KSS is close to 0.7. Overall, the

Table 3. Number of matchup pixels for the target areas.

\begin{tabular}{lcccc}
\hline & \multicolumn{4}{c}{ Matchup Pixels } \\
\cline { 2 - 5 } Target Area & January & April & July & October \\
\hline Area-1 (desert) & 257129 & 739875 & 363660 & 503467 \\
Area-2 (snow) & 403128 & 485133 & 512724 & 266039 \\
Area-3 (ocean) & 464033 & 750941 & 511496 & 600715 \\
Area-4 (forest) & 267594 & 374900 & 339001 & 202888 \\
\hline
\end{tabular}

results are encouraging. For inter-satellite comparisons, a number of reasons can result in disagreements (Taylor et al., 2016). The fundamental reason is the spatial and temporal differences in matchups. The time difference here is defined as 10 minutes. Furthermore, the comparisons are based on the resampling grids with a spatial resolution of $0.01^{\circ} \times 0.01^{\circ}$. The differences in matchups between two sensors could presumably be reasons for some of the disagreements. In addition, the differences in instrumentation and satellite sensors could also lead to discrepancies in cloud-screening comparisons, since the sensors are not viewing the exact same scene with the same viewing geometry at the same time (Taylor et al., 2016).

In order to evaluate the proposed scheme during different seasons, the cloud-screening results of the four target areas are selected from January, April, July and October in 2011. The CCL values for the operational cloud-mask product of MODIS are set as the median values of the ranges that we defined for the four categories derived from scheme III in Fig. 3, which are 0.875 (clear), 0.625 (probably clear), 0.375 (prob-

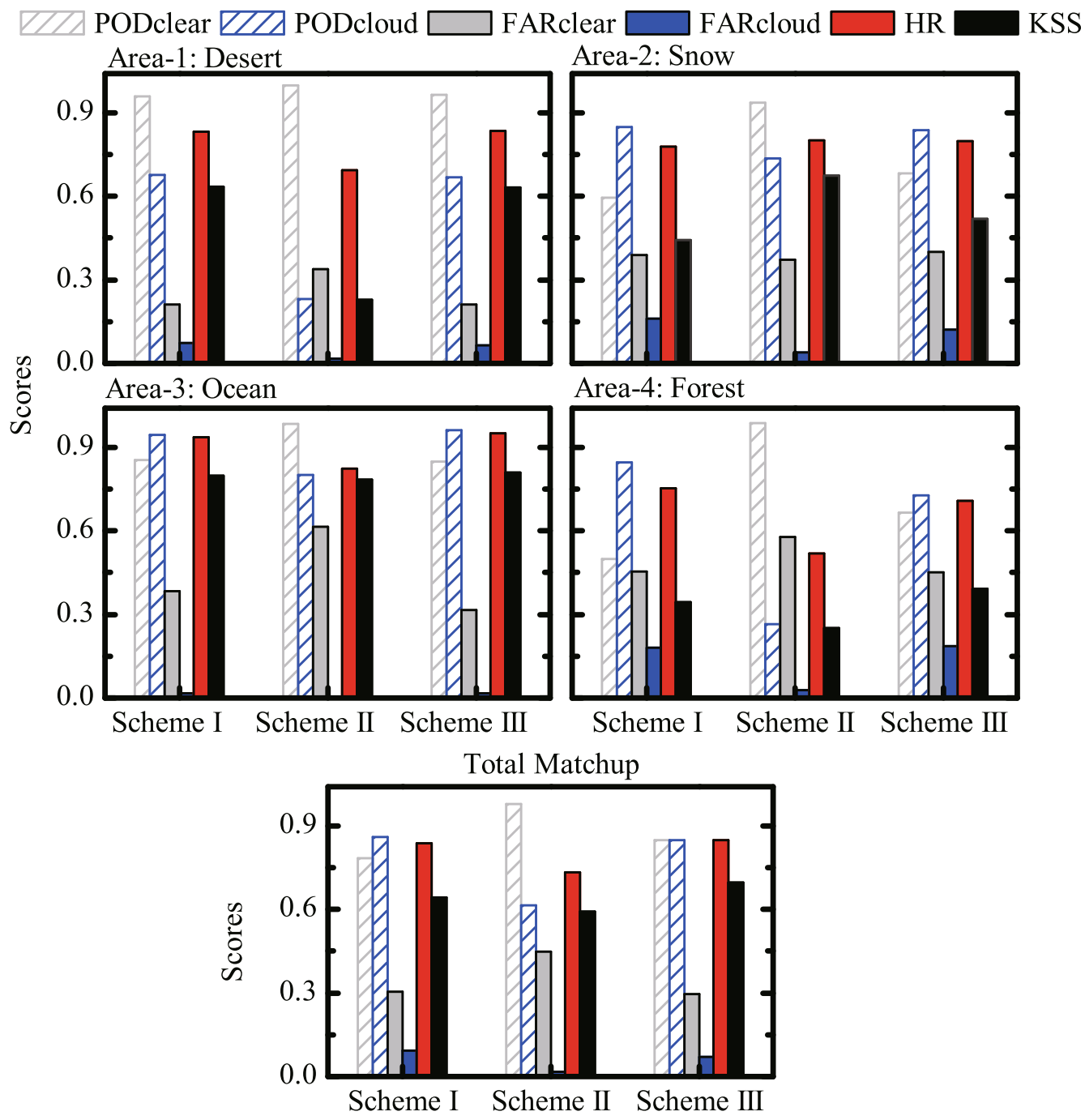

Fig. 4. POD, FAR, HR and KSS scores for the clear-conservative (scheme I), cloud-conservative (scheme II), and the proposed (scheme III) cloud-screening algorithms. 


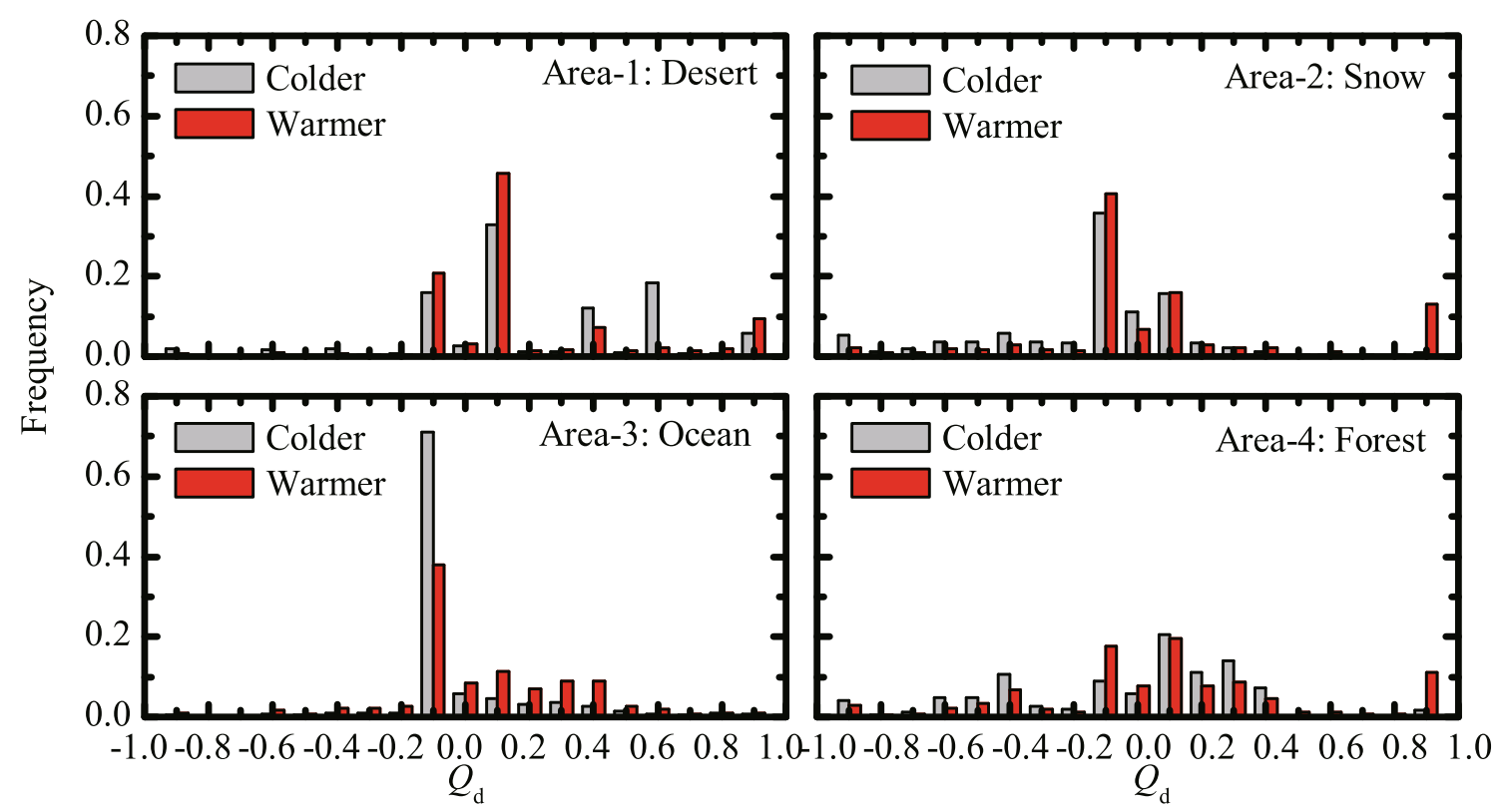

Fig. 5. The distributions of $Q_{\mathrm{d}}$ during different seasons over the target areas.

ably cloudy), and 0.125 (cloudy). We define $Q_{\mathrm{d}}$ as below,

$$
Q_{\mathrm{d}}=Q_{\text {schemeIII }}-Q_{\text {MODIS }},
$$

where $Q_{\text {schemeIII }}$ and $Q_{\text {MODIS }}$ represent the CCL values derived from the proposed scheme and MODIS, respectively. According to the definition, $Q_{\mathrm{d}}$ ranges from -1.0 to 1.0. The distributions of $Q_{\mathrm{d}}$ are illustrated in Fig. 5. The colder seasons include the scenes in January and October. The scenes in April and July belong to warmer seasons. The histogram value for a given bin in Fig. 5 represents the frequency of occurrence of pixels with $Q_{\mathrm{d}}$ bracketed by that bin. For the ocean area, the frequency of occurrence of pixels peaks at the bins with $Q_{\mathrm{d}}$ around -0.1 . For the remaining target areas, the pixels are mainly distributed across the bins with $Q_{\mathrm{d}}$ between -0.1 to 0.1 , implying very little difference between MODIS and scheme III. According to the histogram, there are approximately $10 \%$ of pixels with a $Q_{\mathrm{d}}$ around 0.9 , for the target areas over desert, snow and forest. This is probably due to the erroneous identification of brighter clouds as snow-covered. The results also reveal relatively better performance during warmer seasons, except over the ocean, which is probably due to the poor performance over the sun-glint regions.

\section{Summary}

A cloud-screening scheme for CAPI is presented for the pre-launch period of TANSAT. The work relies upon the use of proxy measurements taken by FY-3A/VIRR. Instead of the traditional regrouping method for threshold tests, the scheme for CAPI classifies each spectral test as either clear- or cloudconservative according to the CCL value derived from the individual test for each pixel. The final CCL of each pixel is determined by combining the results from these two groups.
For sensors with few channels, such as CAPI, this cloudscreening scheme effectively avoids the limitation of the traditional regrouping rules.

The proposed scheme is evaluated over four target areas with typical surface conditions (desert, snow, ocean, forest) in China. It yields good cloud-screening results in all cases, which are highly consistent with the visible images from FY-3A/VIRR. In addition, the performance of the proposed scheme is quantified against the operational cloudmask products from MODIS. The comparison is based on the matchup scenes over the target areas during four studied months (January, April, July and October). The quantitative analysis suggests that the scheme for CAPI has inherited the advantages of the two traditional schemes and shows improvements in cloud screening. The evaluation for seasons reveals that the difference values of the final CCL derived from the proposed scheme and MODIS are mainly distributed between -0.1 to 0.1 . The scheme performs better during warmer seasons, except for areas over ocean.

The thresholds of some tests applied here are directly taken from the CLAUDIA algorithm, in consideration of the similar spectral bands between CAPI and TANSO-CAI. However, the thresholds need to be examined and adjusted to optimize cloud-mask results in the pre-launch period of TANSAT. It relies extensively on the use of the synthetic data of CAPI. The present work does not include the modifications of thresholds, which need further investigation once real CAPI data are available from space.

Acknowledgements. This research was sponsored by the National Basic Research (973) Program of China from the Ministry of Science and Technology of China (Grant No. 2013CB430104) and the Strategic Priority Research Program of the Chinese Academy of Sciences (Grant No. XDA05040201). 
Open Access. This article is distributed under the terms of the Creative Commons Attribution 4.0 International License (http://creativecommons.org/licenses/by/4.0/), which permits unrestricted use, distribution, and reproduction in any medium, provided you give appropriate credit to the original author(s) and the source, provide a link to the Creative Commons license, and indicate if changes were made.

\section{REFERENCES}

Ackerman, S. A., K. I. Strabala, W. P. Menzel, R. A. Frey, C. C. Moeller, and L. E. Gumley, 1998: Discriminating clear sky from clouds with MODIS. J. Geophys. Res., 103, 32 14132158.

Ackerman, S. A., R. E. Holz, R. Frey, E. W. Eloranta, B. C. Maddux, and M. McGill, 2008: Cloud detection with MODIS. Part II: Validation. J. Atmos. Oceanic Technol., 25, 10731086.

Arino, O., J. R. Perez, V. Kalogirou, P. Defourny, and F. Achard, 2010: GlobCover 2009. Proceedings of ESA Living Planet Symposium, 28 June-2 July, Bergen, Norway, 3 pp. [Available online at http://epic.awi.de/31046/1/Arino_et_al_GlobCover 2009-a.pdf.]

Barkley, M. P., P. S. Monks, and R. J. Engelen, 2006: Comparison of SCIAMACHY and AIRS $\mathrm{CO}_{2}$ measurements over North America during the summer and autumn of 2003. Geophys. Res. Lett., 33, L20805.

Bi, Y. M., Z. D. Yang, S. Y. Gu, Q. Wang, L. Gao, and J. Chen, 2014: Impacts of aerosol and albedo on TanSat $\mathrm{CO}_{2}$ retrieval using the near infrared $\mathrm{CO}_{2}$ bands. Proc. SPIE 9259, Remote Sensing of the Atmosphere, Clouds, and Precipitation V, 925915 (November 8, 2014); doi: 10.1117/12.2066123.

Bovensmann, H., J. P. Burrows, M. Buchwitz, J. Frerick, S. Noël, V. V. Rozanov, K. V. Chance, and A. P. H. Goede, 1999: SCIAMACHY: Mission objectives and measurement modes. J. Atmos. Sci., 56, 127-150.

Butz, A., and Coauthors, 2011: Toward accurate $\mathrm{CO}_{2}$ and $\mathrm{CH}_{4}$ observations from GOSAT. Geophys. Res. Lett., 38, L14812, doi: 10.1029/2011GL047888.

Cai, Z. N., Y. Liu, and D. X. Yang, 2014: Analysis of $\mathrm{XCO}_{2}$ retrieval sensitivity using simulated Chinese Carbon Satellite (TanSat) measurements. Science China Earth Sciences, 57, 1919-1928.

Chahine, M., C. Barnet, E. T. Olsen, L. Chen, and E. Maddy, 2005: On the determination of atmospheric minor gases by the method of vanishing partial derivatives with application to $\mathrm{CO}_{2}$. Geophys. Res. Lett., 32, L22803, doi: 10.1029/2005GL 024165.

Chahine, M. T., and Coauthors, 2006: AIRS: Improving weather forecasting and providing new data on greenhouse gases. Bull. Amer. Meteor. Soc., 87, 911-926.

Cox, P. M., R. A. Betts, C. D. Jones, S. A. Spall, and I. J. Totterdell, 2000: Acceleration of global warming due to carbon-cycle feedbacks in a coupled climate model. Nature, 408, 184-187.

Crisp, D., C. E. Miller, and P. L. Decola, 2008: NASA Orbiting Carbon Observatory: Measuring the column averaged carbon dioxide mole fraction from space. Journal of Applied Remote Sensing, 2, 023508.

Dong, C. H., and Coauthors, 2009: An overview of a New Chinese weather satellite FY-3A. Bull. Amer. Meteor. Soc., 90, 15311544.
Farquhar, G. D., 1997: CLIMATE CHANGE: Carbon dioxide and vegetation. Science, 278, 1411.

Frey, R. A., S. A. Ackerman, Y. H. Liu, K. I. Strabala, H. Zhang, J. R. Key, and X. Wang, 2008: Cloud detection with MODIS Part I: Improvements in the MODIS cloud mask for collection 5. J. Atmos. Oceanic Technol., 25, 1057-1072.

Gao, B. C., A. F. H. Goetz, and W. J. Wiscombe, 1993: Cirrus cloud detection from Airborne Imaging Spectrometer data using the $1.38 \mu \mathrm{m}$ water vapor band. Geophys. Res. Lett., 20 , 301-304.

Gesell, G., 1989: An algorithm for snow and ice detection using AVHRR data: An extension to the APOLLO software package. Int. J. Remote Sens., 10, 897-905.

Hall, D. K., and G. A. Riggs, 2011: Normalized-difference snow index (NDSI). Encyclopedia of Snow, Ice and Glaciers, V. P. Singh, P. Singh, and U. K. Haritashya, Eds., Springer, 779780 .

Hall, D. K., G. A. Riggs, and V. V. Salomonson, 1995: Development of methods for mapping global snow cover using moderate resolution imaging spectroradiometer data. Remote Sensing of Environment, 54, 127-140.

Hall, D. K., G. A. Riggs, V. V. Salomonson, N. E. DiGirolamo, and K. J. Bayr, 2002: MODIS snow-cover products. Remote Sensing of Environment, 83, 181-194.

He, Q.-J., 2011: A daytime cloud detection algorithm for FY3A/VIRR data. Int. J. Remote Sens., 32, 6811-6822.

Hulley, G. C., and S. J. Hook, 2008: A new methodology for cloud detection and classification with ASTER data. Geophys. Res. Lett., 35, L16812.

Hutchison, K. D., B. D. Iisager, and B. Hauss, 2012: The use of global synthetic data for pre-launch tuning of the VIIRS cloud mask algorithm. Int. J. Remote Sens., 33, 1400-1423.

Hutchison, K. D., J. K. Roskovensky, J. M. Jackson, A. K. Heidinger, T. J. Kopp, M. J. Pavolonis, and R. Frey, 2005: Automated cloud detection and classification of data collected by the Visible Infrared Imager Radiometer Suite (VIIRS). Int. J. Remote Sens., 26, 4681-4706.

Ishida, H., and T. Y. Nakajima, 2009: Development of an unbiased cloud detection algorithm for a spaceborne multispectral imager. J. Geophys. Res.: Atmos., 114, D07206, doi: 10.1029/ 2008JD010710.

Ishida, H., T. Y. Nakjima, T. Yokota, N. Kikuchi, and H. Watanabe, 2011: Investigation of GOSAT TANSO-CAI cloud screening ability through an intersatellite comparison. J. Appl. Meteor. Climatol., 50, 1571-1586.

Karlsson, K.-G., and A. Dybbroe, 2010: Evaluation of Arctic cloud products from the EUMETSAT Climate Monitoring Satellite Application Facility based on CALIPSO-CALIOP observations. Atmos. Chem. Phys., 10, 1789-1807.

Kriebel, K. T., R. W. Saunders, and G. Gesell, 1989: Optical properties of clouds derived from fully cloudy AVHRR pixels Beitr. Phys. Atmos., 62, 165-171.

Kriebel, K. T., G. Gesell, M. Kästner, and H. Mannstein, 2003: The cloud analysis tool APOLLO: Improvements and validations. Int. J. Remote Sens., 24, 2389-2408.

Kuze, A., H. Suto, M. Nakajima, and T. Hamazaki, 2009: Thermal and near infrared sensor for carbon observation Fouriertransform spectrometer on the Greenhouse Gases Observing Satellite for greenhouse gases monitoring. Appl. Opt., 48, 6716-6733.

Liu, Y., and Coauthors, 2013: Development of Chinese carbon dioxide satellite (TanSat). EGU General Assembly, Vienna, 
Austria, 157-189.

Le Quéré, C., and Coauthors, 2009: Trends in the sources and sinks of carbon dioxide. Nature Geo., 2, 831-836.

Nakajima, T. Y., T. Tsuchiya, H. Ishida, T. N. Matsui, and H. Shimoda, 2011: Cloud detection performance of spaceborne visible-to-infrared multispectral imagers. Appl. Opt., 50, 2601-2616.

Platnick, S., M. D. King, S. A. Ackerman, W. P. Menzel, B. A. Baum, J. C. Riedi, and R. A. Frey, 2003: The MODIS cloud products: Algorithms and examples from Terra. IEEE Trans. Geosci. Remote Sens., 41, 459-473.

Reuter, M., M. Buchwitz, O. Schneising, J. Heymann, H. Bovensmann, and J. P. Burrows, 2010: A method for improved SCIAMACHY $\mathrm{CO}_{2}$ retrieval in the presence of optically thin clouds. Atmospheric Measurement Techniques, 3, 209-232.

Riggs, G. A., and D. K. Hall, 2004: Snow and cloud discrimination factors in the MODIS snow algorithm. Preprints, 2004 IEEE International Geoscience and Remote Sensing Symposium, Anchorage, AK, 3714-3716.

Rossow, W. B., 1989: Measuring cloud properties from space: A review. J. Climate, 2, 201-213.

Rossow, W. B., and L. C. Garder, 1993: Cloud detection using satellite measurements of infrared and visible radiances for ISCCP. J. Climate, 6, 2341-2369.

Rossow, W. B., L. C. Garder, and A. A. Lacis, 1989: Global, seasonal cloud variations from satellite radiance measurements. Part I: Sensitivity of analysis. J. Climate, 2, 419-458.

Saunders, R. W., and K. T. Kriebel, 1988: An improved method for detecting clear sky and cloudy radiances from AVHRR data. Int. J. Remote Sens., 9, 123-150.

Sèze, G., and W. B. Rossow, 1991: Time-cumulated visible and infrared radiance histograms used as descriptors of surface and cloud variations. Int. J. Remote Sens., 12, 877-920.
Shi, G. M., C. C. Li, and T. Ren, 2014: Sensitivity analysis of single-angle polarization reflectance observed by satellite. Chin. Sci. Bull., 59, 1519-1528.

Solomon, S., G.-K. Plattner, R. Knutti, and P. Friedlingstein, 2009: Irreversible climate change due to carbon dioxide emissions. Proceedings of the National Academy of Sciences of the United States of America, 106, 1704-1709.

Stowe, L. L., S. K. Vemury, and A. V. Rao, 1994: AVHRR clearsky radiation data sets at NOAA/NESDIS. Advances in Space Research, 14, 113-116.

Stowe, L. L., E. P. McClain, R. Carey, P. Pellegrino, G. G. Gutman, P. Davis, C. Long, and S. Hart, 1991: Global distribution of cloud cover derived from NOAA/AVHRR operational satellite data. Advances in Space Research, 11, 51-54.

Taylor, T. E., and Coauthors, 2016: Orbiting Carbon Observatory2 (OCO-2) cloud screening algorithms: validation against collocated MODIS and CALIOP data. Atmospheric Measurement Techniques, 9, 973-989.

Vogel, S. W., 2002: Usage of high-resolution Landsat 7 band 8 for single-band snow-cover classification. Annals of Glaciology, 34, 53-57.

Wang, X., W. Li, Y. Zhu, and B. Zhao, 2012: Improved cloud mask algorithm for FY-3A/VIRR data over the northwest region of China. Atmospheric Measurement Techniques, 5, 8189-8222.

Yokota, T., Y. Yoshida, N. Eguchi, Y. Ota, T. Tanaka, H. Watanabe, and S. Maksyutov, 2009: Global concentrations of $\mathrm{CO}_{2}$ and $\mathrm{CH}_{4}$ retrieved from GOSAT: First preliminary results. Scientific Online Letters on the Atmosphere: SOLA, 5, 160-163.

Yoshida, Y., and Coauthors, 2013: Improvement of the retrieval algorithm for GOSAT SWIR $\mathrm{XCO}_{2}$ and $\mathrm{XCH}_{4}$ and their validation using TCCON data. Atmospheric Measurement Techniques, 6, 1533-1547. 